\title{
Critical Thinking and Feminism
}

\author{
KAREN J. WARREN Macalester College
}

\section{Introduction: \\ Critical Thinking and Feminism}

What does feminism have to do with critical thinking? What can a political movement, feminism, contribute to an understanding of a reflective activity, critical thinking? If critical thinking is a feminist issue, what makes it so?

In this paper I suggest answers to these questions by raising two sorts of worries about current conceptions of critical thinking from a feminist perspective. The first and primary worry concerns the nature of critical thinking and the critical thinker. The second concerns the learning/teaching of critical thinking. Underlying this twofold worry is the view that an adequate understanding of critical thinking-both what it is and how it is taught-must involve a recognition of the importance of conceptual frameworks. I argue that since critical thinking always occurs within a conceptual framework, what is needed is a contextual understanding of critical thinking, i.e. one which acknowledges the ways in which conceptual frameworks affect the sort of thinking we do. Furthermore, I argue that insofar as a given conceptual framework is biased, the critical thinking which grows out of and reflects it will inherit this bias. Just as patriarchy is the special interest of feminists, it is patriarchal conceptual frameworks and the bias they generate which is of special interest to a feminist critique of critical thinking.

\section{The Nature of Critical Thinking}

While there is no single definition of critical thinking which is accepted by all specialists, ${ }^{1}$ it is sufficient for our purposes to use the term as it is frequently used in the literature and as it has been used by Robert
Ennis: Critical thinking is reasonable reflective thinking that is focused on deciding what to believe or do. ${ }^{2}$

Critical thinking so defined involves both abilities (or skills) and dispositions (or, tendencies). Setting aside taxonomical questions about classification, a typical list of critical thinking abilities and dispositions includes several of special interest in this paper: the abilities of deducing and assessing deductions, inducing and assessing inductions, identifying and assessing assumptions, observing and assessing observation reports, identifying and assessing the credibility of a source, detecting and avoiding unnecessary and avoidable bias, identifying and assessing generalizations, identifying and assessing causal claims; and, the dispositions of openmindedness and interpersonal sensitivity. ${ }^{3}$

Notice that this broad definition of critical thinking in terms of both abilities and dispositional aspects allows that creative thinking, passion, and empathy may play important roles in "reasonable reflection" about what to do or believe ${ }^{4}$ Critical thinkers are those who exercise such skills and display such dispositions. This broad definition also allows for the important role knowledge, especially background or prior knowledge, plays in one's ability to think critically.

\section{Feminism and Patriarchal Conceptual Frameworks}

Although there are important differences among the variety of feminisms (e.g. liberal feminism, tradtional Marxist feminism, radical feminism, socialist feminism, Black and Third World feminism, ecological feminism), all feminists agree that feminism is (at least) the movement to end sexist oppression. ${ }^{5}$ All feminists agree that sexism ex- 
ists, that it is wrong, and that it must be eliminated. As such, all feminists are opposed to patriarcy, i.e. the systematic domination of women by men.

Contemporary feminists claim that, whether we know it or not, each of us operates out of a historically and socially constructed "frame of reference," "world view," or what I am calling "conceptual framework, "' i.e. a set of basic beliefs, values, attitudes, and assumptions which explain, shape, and reflect our view of ourselves and our world. Conceptual frameworks are influenced by such factors as sex-gender, class, race/ethnicity, age, affectional preference, and nationality. Although one's conceptual framework can change, all individuals perceive and construct what they perceive, know, and value through some conceptual framework. At any given time, a conceptual framework functions for an individual as a finite lens, a "field of vision," in and through which information and experiences are filtered. As such, conceptual frameworks set boundaries on what one "sees."

Some conceptual frameworks are oppressive. For our purposes, there are three typical features of oppressive conceptual frameworks, at least in Western societies, for an understanding of women's oppression. ${ }^{6}$ First, an oppressive conceptual framework typically is characterized by valuehierarchical thinking. As I am using the expression, value-hierarchical thinking (as distinguished from "'hierarchial thinking") is "a perception of diversity which is so organized by a spatial metaphor (Up-andDown) that greater value is always attributed to that which is higher." 7 Value-hierarchical thinking has put men "up" and women "down," culture "up" and nature "down," minds "up" and bodies "down," reason or intellect "up" and emotion "down.",

Second, an oppressive conceptual framework typically supports the sort of "either-or" thinking which posits inappropriate or misleading or harmful value dualisms, i.e. either-or pairs in which the disjunctive terms are seen as exclusive (rather than inclusive) and oppositional (rather than complementary), and where higher value is attributed to one disjunct than the other. Value dualisms not only condition how one perceives and describes reality (viz. evaluatively dualistically); they also conceptually separate as opposite aspects of reality that may in fact be inseparable or complementary, e.g. reason and emotion. ${ }^{9}$ As will be illustrated, such uses of value dualisms may be inappropriate, misleading, or harmful.

The third and most important feature of an oppressive conceptual framework is that it gives rise to a logic of domination, i.e. a structure of argumentation which explains, justifies, and maintains the subordination of an "inferior"' group by a "'superior"' group on the grounds of the (alleged) superiority and inferiority of the respective groups. Since it is the logic of domination which supplies the missing assumption that superiority justifies subordination, it is the logic of domination which gives the final moral stamp of approval to the "justified" subordination of that which is deemed lower or less valuable. ${ }^{10}$

Many contemporary feminists are interested in oppressive conceptual frameworks that are patriarchal, i.e. ones in which historically or traditionally male genderidentified beliefs, values, attitudes, and assumptions are taken as the only, or the standard, or the more highly valued ones than female gender-identified ones. ${ }^{11}$ Historical$l y$, a patriarchal conceptual framework has assigned greater value, status, or prestige to that which traditionally has been identified as "male" than to that which traditionally has been identified as "'female," or carves out different spheres (e.g. the "public" sphere of the polls and the "private" sphere of the home) and gives value to what is femaleidentified only within that female-identified and relatively lower status sphere. ${ }^{12}$ Conceptually, a patriarchal conceptual framework functions to maintain the subordination of women. ${ }^{13}$

It is by understanding the nature and power of conceptual frameworks, particularly oppressive and patriarchal ones, that one can see the respects in which critical thinking is a feminist issue. It is to this topic that I now turn.

\section{Critical Thinking as a Feminist Issue}

Any issue is or could be a feminist issue. 
What makes any issue a feminist issue is that an understanding of it contributes in some way to an understanding of the oppression of women. Lack of comparable pay for comparable work is a feminist issue wherever and whenever an understanding of it bears on an understanding of the oppression of women. Carrying water is a feminist issue if, in a given culture, it is the women who spend several hours a day carrying water and that activity contributes to their unequal, inferior, or subordinate status.

Critical thinking is a feminist issue because there are important ways in which an understanding of critical thinking bears on an understanding of the subordination of women. The basic link or connection provided in this paper between the two-critical thinking and feminism-is located in the nature of conceptual frameworks, especially oppressive patriarchal ones. ${ }^{14}$

Critical thinking does not occur in a vacuum; it always occurs within some conceptual framework. Stated differently, when one does the sorts of things critical thinkers do, e.g. observe, infer, generalize, predict, define, make assumptions, give causal explanations, there is always some point of view which is the point of view of the critical thinker. The so-called ideal of a "neutral observer, ' i.e. one who has no point of view is, at best, an ideal, and at worst, an "ideological prejudice." I5

Recent feminist scholarship in two different areas-science and ethics-reveal the importance of conceptual frameworks. Consider ways in which feminist challenges in these two areas bears on an understanding of what makes critical thinking a feminist issue. ${ }^{16}$

Feminist Science. In her book Science and Gender, neurophysiologist Ruth Bleier argues that "science is not the neutral, dispassionate, value-free pursuit of Truth." ${ }^{17}$ According to Bleier, traditional or dominant science occurs within androcentric conceptual framework and inherits the androcentric bias of that framework. ${ }^{18}$ Bleier and other feminist scientists have defended their charge that male gender-bias arises in two areas of scientific research in which important critical thinking skills are used: so-called "sex differences" research between men and women, and primatology.

"Sex Differences" Research. Suppose an assumption of a given conceptual framework is that there is a meaningful distinction between "pure biology" and "environment" (or "culture"'). Within such a framework, the question "Are there genetic sex-based differences in men's and women's behaviors?' makes sense. Research projects and methodologies aimed at isolating sex-linked differences in brain structure, hemispheric lateralization, hormones, or genes to explain behavior differences between "the sexes" (e.g. in verbal fluency, mathematical skill, visualspatial information processing skills, or cognitive abilities) are countenanced, and conclusions about purely biological bases for male superiority in certain activities are offered as empirically verified or verifiable.

However, what if the initial assumption about the dichotomy between pure biology and environment is false or conceptually flawed? Then the controversy about purely genetic, inherited, sex-based behavior traits itself, including the questions asked, the research projects undertaken, the methodologies employed, and the answers given, is also conceptually flawed.

This is what feminist scientists like Ruth Bleier argue. They claim that the question "Are there biological sex differences between men and women?" is conceptually flawed, since it is not possible to separate off any "pure"' biology from culture in the requisite way. ${ }^{19}$ Stated differently, in order for the question to be meaningfully raised at all, one must presuppose the legitimacy of the very biology/culture dualism that feminist scientists like Bleier deny. Furthermore, if the question "Are there biological sex differences between men and women?' ' is conceptually flawed, then so is any conceptual framework which countenances a debate over sex differences, since it will also mistakenly assume that it does make sense to talk of a "pure" biology separate from culture, that one can measure how much of human behavior can be attributed to pure biology and how much to environment and learning, and that any differences in behaviors between men and 
women-socially constructed gender categories-is based in pure biology. This is especially important to notice since, historically, assumptions about "sex differences" have functioned to explain and justify the alleged "natural" or "innate" inferiority of "the female sex" and the biological basis of women's oppression in her childbearing and childrearing roles.

If the views of feminist scientists such as Ruth Bleier are correct (no attempt is made to defend them here) and "sex difference", research is conceptually flawed, then so is any conceptual framework which sanctions, maintains, or gives rise to the meaningfulness of such research. The point here is not whether the distinction between "pure biology" and "environment" is patriarchally motivated or causally linked to a patriarchal conceptual framework; establishing that would be a different task. The point here is that the sort of conceptual framework which sanctions, maintains, or gives rise to such value-laden " "either-or" thinking is flawed. Since feminist scientists claim that "'sex-differences research" is comfortably housed in dominant science, and that dominant science reflects a patriarchal conceputal framework, then, if they are correct, "sex-differences research" is comfortably housed within a patriarchal conceptual framework-one which has historically functioned to value as inferior or lower-status whatever is genetically or biologically linked with "the female sex," or has historically sanctioned "sex difference" conclusions about superior male abilities and behavior over female abilities and behavior. Understood in this way, the feminist objection to "sex differences research" done from within an oppressive conceptual framework is that it takes as meaningful and tenable the either-or (and not both) distinction between "pure genetics" and "environment" and mistakenly assumes that information about genetics alone will explain human behavior. The feminist position that biology is both genetic and cultured, both determined and conditioned, is never entertained. For feminist scientists, it isn't so-called "biological differences"' (whatever they are) between males and females that is really at issue, but the values, beliefs, attitudes and assumptions about biological differences and about the relevance of such differences for how men and women are viewed and treated that is at issue. And to get at that issue is to get at the nature and significance of conceptual frameworks.

Primatology. Feminist primatologists such as Donna Haraway and Sarah Hrdy ${ }^{20}$ have challenged traditional androcentric observational and explanatory models for primate social organization. The assumption of such models was that primate social organization was structured around "male dominance hierarchies." If any attention was focused on observing female primate behavior, females were cast in passive and primarily nurturing roles, while males were cast in culturally stereotyped and sanctioned active, courting, and promiscious roles. Assumptions of "male dominance hierarchies" prevented primatologists from seeing "the full extent of female choice, initiative and aggressivity or its polyandrous expression," and from seeing that dominance hierarchies are neither universal nor always male. ${ }^{21}$ It prevented researchers from seeing, for example, that it is usually estrous females that select mating partners, that in some species (e.g. Japanese macaques, rhesus macaques, and vervets) species dominance is matrilineal, and that no evidence supports the view that dominant males have more frequent access to females than less dominant males in baboon troops. ${ }^{22}$ As Bleier writes,

In the absence of knowledge about female
primates based on observations of their behaviors,
primatologists then felt free to speculate (that is,
to construct) female primates in ways that allow-
ed their imagined behaviors and characteristics
to fit existing male-centered theories of human
cultural evolution and thus to embellish,
naturalize, and reinforce the social construction
of human female and male genders and of rela-
tions of domination and subordination. 23

Again, if this view is correct (and I do not attempt here to defend the view that it is), then the basic beliefs, values, attitudes, and assumptions which describe a patriarchal conceptual framework blinded these researchers from raising and addressing crucially relevant issues about "male dominance hierarchies" and female primate behavior. The "point of view" of these researchers does not permit 
such issues to get raised at all. (More is said about this in connection with the discussion of assumptions, below.)

Feminist Ethics. One target of feminist criticisms of gender-bias in contemporary Western philosophy is the dominant "rights/rules ethic," i.e. an ethical framework for assessing moral conduct in terms of alleged rights of relevant parties and/or in terms of governing rules or principles, appeal to which provides a decisionprocedure for resolving conflicts among rights. This ethical framework is essentially hierarchical or "pyramidal," where the "authority" of a right or rule is given from the top of the hierarchy.

Judith Thomson's discussion of abortion in her well-known article, "A Defense of Abortion" 24 is characteristic of a discucssion within a rights/rules framework. Thomson critiques the argument that since a fetus' right to life overrides a pregnant woman's right to decide what shall happen in and to her body, abortion is wrong. She does so not by challenging the rights/rules framework in which that argument occurs, but by challenging the truth of the claim that a fetus' right to life overrides a pregnant woman's right to decide.

Feminist philosophers like Kathryn Addelson raise several objections to "the Thomson tradition" approach to discussions of abortion. ${ }^{25}$ First, it represents moral situations in a value-hierarchial way which conceals that "the point of view" from the top of the hierarchy is an invisible, unmarked, and hence privileged point of view of the dominant group (historically white males), while the point of view of the "other" (women, blacks) functions as a value-laden, biased, or marked point of view. A judge is a judge unless she is female or black. A philosopher is a philosopher unless she is feminist; then she is a feminist philosopher. And the Western philosophical tradition is just that until it is critiqued by feminists who insist on marking it as "the white male dominant Western philosophical tradition.' 'It is not, as traditional philosophers have assumed, an ungendered, unraced, or unclassed point of view.
Addelson argues that the sort of bias that infects the Thomson approach to abortion "allows moral problems to be defined from the top of various hierarchies of authority in such a way that the existence of the authority is concealed." 26 By concealing the authority (e.g. of traditional academic philosophers), the point of view from the top of the hierarchy appears to be impartial when it is not. Furthermore, according to Addelson, since the Thomson tradition systematically ignores discussions of hierarchy, dominance, and subordination, it does not provide an adequate conception of ethics from the point of the experiences of women (including poor, pregnant women) in subordinate positions.

Second, a rights/rules approach to abortion incorrectly assumes that talk of rights adequately captures all the morally relevant features of abortion. Other morally relevant data, e.g. what Jane Martin calls the " 3 C's of caring, concern, and connection" 27 either do not get included at all, or, if they do, get included only insofar as they can be unpacked in terms of the relevant moral categories of property, rules, and rights of moral agents.

For these two sorts of reasons, feminists like Addelson object that a rights/rules approach to abortion incorrectly assumes that a rights/rules framework provides an objective, impartial, and universalizable decisionprocedure for resolving moral conflicts such as abortion; what (they claim) it really provides is a decision-procedure which grows out of a value-hierarchical, historically wellentrenched system of social relationships which assumes that "authority" (objectivity, impartiality, universalizability) is given from the top of the hierarchy-the dominant group. ${ }^{28}$

As with the preceeding discussion of feminist science, the point here is neither to defend the feminist positions given by Addelson and others, nor to establish some sort of logical entailment relation between a "rights/rules ethic" and male-dominance value-hierarchies (even if such an entailment relationship could be shown to exist). Rather, the point is to suggest that if the view of feminists like Addelson is correct, viz. that a rights/rules ethic within a hierarchical social system of male dominance, whatever else its 
virtues or strengths, has historically functioned as if it were an observer-neutral position when it is not and has not been, then use of a rights/rules ethic within a patriarchal conceptual framework serves to explain, maintain, and justify the point of view of those " on top" as an unmarked and unprivileged point of view (e.g. of the "rational," or "objective," or "detached and impartial," or "'neutral observer") when it is not. Calling attention to the nature and power of historically constructed patriarchal conceptual frameworks is part of what makes this historical and contemporary feature of a rights/rules ethic visible.

\section{Feminist Science, Feminist Ethics, and Critical Thinking}

If what I have said so far is plausible, then critical thinking in and about science and critical thinking in and about ethics requires recognition of the ways in which the exercise of important critical thinking skills and dispositions is not always easy to do, and is sometimes impossible to do, within a patriarchal conceptual framework. A consideration of a few such selected skills and dispositions will show why this is so.

1. Recognizing and assessing an assumption. When an assumption is basic to a conceptual framework, it may not always be possible to challenge or revise the assumption and yet remain within that framework. It is impossible when the framework itself presupposes the truth of the claim one is denying. In such a case, the framework itself must be changed; no reformist moves from within the framework (e.g. changing the meanings of some terms or altering otherthan-basic assumptions) will remedy the defect.

This issue, the "reform or revolution" issue-change from within or change from without-arises in all areas of contemporary feminist scholarship. For example, it arises in "feminist curricular transformation projects," i.e. feminist discussions of ways to change the traditional or "mainstream" curriculum to make it more inclusive of women. There, the "reform or revolution" issue often arises in connection with the "add women and stir approach" to curriculum development. As one "adds" women-particularly feminist women-to traditional science or ethics courses, for instance, one soon realizes that the inclusion of women begins to challenge the way in which science and ethics are conceived, the way each is taught and practiced, and which issues get labeled as bona fide "scientific" or "ethical" issues. This is because, in the words of Elizabeth Minnick, one cannot simply add the idea that the world is round to the idea that the world is flat. Some ideas or assumptions simply don't mix. When they do not, the result one gets is more like an explosion than a mixture. The idea that there is no clear conceptual distinction between biology and culture cannot simply be added to the idea that there is a clear conceptual distinction between biology and culture. The idea that animal dominance hierarchies are neither universal nor male cannot be added to the idea that they are. The ideas that there is androcentric bias in science and ethics (even if "only" a historical bias rather than one "in the nature of things"), and that there currently is no value-neutral, objective, and impartial view in science or in ethics, cannot simply be added to the ideas that there is no such bias or that there is a value-neutral, objective, and impartial point of view in science and ethics. In each of these cases, to adopt a feminist-identified stance is to deny some of the main assumptions of traditional science and ethics, and thereby to abandon, at least on these issues, the conceptual framework which gives rise to them.

2. Observing and judging observation reports. As has been suggested already, what an author notices or fails to notice, what she takes as "given" in what she observes, or what she considers relevant or credible or a reason, is ultimately affected by the conceptual framework through which she does the observing and assessing. Feminist neurophysiologists looking at a cluster of cells under a microscope may take very different observations than traditional scientists engaged in observing cells. Feminist scientists like Ruth Bleier who assume that there is no "pure" biology separate from environment or "culture," that cells are "cultured," look 
for interconnections among cells when observing cells. ${ }^{29}$ Any generalizations, predictions, correlations, or causal claims offered based on those observations will stress the complex interconnections among multiple (not single or "linear") biological mechanisms and environmental factors. ${ }^{30}$ Single-cause theories will be higly unlikely, if not impossible, to give.

Similarly, feminist primatologists will reject as unwarranted extrapolations from observations about rodents and primates to generalizations, predictions, or causal explanations about purely biological explanations of human behaviors, because "rodent or monkey behavior is not basic behavior minus culture." 31 The basic assumption on which such extrapolations are based is flawed. And feminist ethicists will insist on including observations based on women's felt experiences of abortion among the morally relevant data of ethical theory-building and conflict resolution regarding abortion.

3. Identifying and assessing causal claims. One helpful test for assessing causal claims is given by Mary Anne Wolff's acronym "CPROOF:" To assess the adequancy of a causal claim, establish a correlation between events to be explained, precedence of some events relative to others, and then rule out other factors. How would one apply "CPROOF", to the "sex-difference research" on human and primate behaviors which is conducted from within a patriarchal conceptual framework? It is difficult, if not impossible, to apply the test since included among the crucial factors that need to be ruled out is the very assumption that is necessary to generate the research in the first place, viz. that it is possible to conduct biological sexbased research "uncontaminated" by the culture. Unless that assumption gets challenged, any explanations or causal claims based on it will be highly suspect, if not simply wrongheaded and ill-conceived. ${ }^{32}$ This is worth noticing because the CPROOF test is a perfectly good test. It is just that it is not a test one cannot effectively or adequately use within a patriarchal conceptual framework by one who subscribes to that framework when that very conceptual framework is characterized by basic assumptions, the falsity of which would have to be challenged in order to adequately apply the CPROOF test. To do so one needs to challenge the patriarchal conceptual framework itself-an activity which those who subscribe to it for as long as they subscribe to it cannot consistently undertake.

The influence of patriarchal conceptual frameworks is not limited to critical thinking skills. There are also conceptually-bound limits on one's ability to exercise important critical thinking dispositions as well. Consider a mainstay disposition, "openmindedness."

4. Openmindedness. It is difficult, if not impossible, to consider seriously other points of view than one's own if one is not aware that there are other points of views. Suppose, for instance, that a fundamental and invisible assumption of one's conceptual framework is that science is objective or value-neutral, or that there is a basic distinction between "innate" biology and learned culture. It then will be extremely difficult, if not impossible, to take seriously the view that science is androcentric, that there are no innate biological differences between men and women (even if there are some between males and females), or that women's childbearing and childrearing roles are not an inevitable consequence of her anatomy. ${ }^{33}$

One thing this shows is that the extent of one's willingness and ability to be openminded about issues is significantly affected by the conceptual framework out of which one operates. Openmindedness is a disposition that persons do or do not exercise within a given conceptual framework. This is the essentially contextual nature of openmindedness: it is always exercised from within a (some) conceptual framework. Notice that this view of openmindedness does not conflict with the view that openmindedness includes being receptive ("open") to points of view different than one's own on a given topic or issue. In some conceptual frameworks, the basic beliefs, values, attitudes, and assumptions of the framework might make being "open" to quite different points of view quite easy, e.g. a conceptual framework in which a basic belief is that one must always be open to differing points of view. Whether such a conceptual framework is a desirable one or not, of 
course, is a separate and, as I suggest shortly, a debatable issue.

Suppose this view of the contextual nature of openmindedness is correct. What, then, is required of persons in order for them properly to be said to be openminded? From within a given conceptual framework, certain positions, claims, or points of view may be viewed as undeserving of serious and equal consideration. Consider, for example a feminist conceptual framework, e.g. one that views women as equal to men, views the subordination of women as wrong, and rejects any claim to a biological "innateness" of gender differences. From within that framework, the claim that women are innately inferior to men not only will not get "equal treatment;" it cannot really be raised at all. It cannot be raised for two related reasons: first, none of the assumptions necessary to give rise to the claim are included within the conceptual framework; second and more importantly, the assumptions necessary to give rise to the claim are logically incompatible with the basic and defining assumptions of the feminist conceptual framework, and so cannot consistently be added to it. It is a variation of the "add women and stir" problem again. Feminists who take the time to address such arguments may do so because such arguments are taken seriously in a patriarchal conceptual framework, or because they want to defeat such arguments. Since the successes of feminism involved the defeat or undermining of patriarchal conceptual frameworks, it is important that someone defeat or undermine such arguments. Still, given the sorts of beliefs, attitudes and value commitments that characterize his world view as "feminist," and given the fact of finite time, resources, and energy, he may choose to pay them no heed.

Is a feminist who chooses not to take seriously arguments for the conclusion that women are innately inferior to men failing to be openminded? Or, is a feminist who chooses not to take seriously arguments for the genetic inferiority of Black people to Anglos failing to be openminded? The answer is "Yes" only if one assumes (as I do not) that openmindedness requires "considering seriously other points of view than one's own" without regard for the truth, bias, or prejudice of those points of view. But the answer is "No" if one assumes otherwise and recognizes that openmindedness always takes place within some conceptual framework. From a feminist point of view, some conceptual frameworks are better than others, and not all positions are worthy of equal consideration. From a feminist point of view, being openminded does not necessarily require that all points of view be given equal consideration; some points of view simply may not warrant such consideration. From a feminist point of view, contemporary Western society is thoroughly structured by race, class, and sex/gender factors; as such, in contemporary Western society at least, there is no currently available valueneutral conceptual framework within which the trait of openmindedness can be exercised. From a feminist point of view, then, a feminist who chooses not to take seriously arguments for the innate inferiority of women or people of color is not being "closeminded.",34

At this point a critic might object as follows: Feminists who choose not to take seriously non-feminist or anti-feminist viewpoints are "partial" or "biased." Since such bias or partiality is incompatible with openmindedness, feminists who take such a stand fail to be openminded. By extension, since openmindedness is an important critical thinking disposition, feminsits who take such a stand also fail to be critical thinkers (or good critical thinkers).

A feminist could respond to this objection in either of two ways. She could argue either that a feminist view is not biased, or that it is biased, but a better bias than the alternatives. Which response is most appropriate depends on what counts as bias. In one sense of 'bias,' the charge of bias attaches to such items as assumptions, reasons, conclusions, or conceptual frameworks which are based on false or faulty generalizations (a common conception of bias). ${ }^{35}$ In this sense of 'bias,' feminist bias arises in the same sort of way that bias arises in generalizations generally, viz. through stereotyping, too small a sample size, a skewed sample that is not representative of the total population, or a generalization from one case only. One determines bias 
by assessing the reasons or evidence offered.

A patriarchal conceptual framework is biased (in this sense) insofar as the sorts of reasons or evidence it offers or countenances, the assumptions on which it is based and the conclusions it warrants produce false or faulty generalizations, e.g. about biologically based sex-differences between men and women, or male dominance in primate societies. Is a feminist conceptual framework biased? Insofar as it rejects as false claims that are indeed false, or rejects as conceptually flawed distinctions that are indeed conceptually flawed, or does not seriously consider reasons, arguments, or data based on such false or flawed claims, it is not biased, or not biased in the way in which patriarchal conceptual frameworks are biased.

However, a feminist point of view may be "biased" or "partial" in a different sense, a sense in which all conceptual frameworks, all points of view, are "biased" or "partial." In this second sense of 'bias', a claim, position, or conceptual framework is biased if it is not value-neutral or objective. Since a conceptual framework is, by definition, based on certain basic beliefs, values, attitudes, and assumptions which permit certain sorts of reasons and omit others, it is biased (in this second sense). This sort of bias makes certain claims from within a given conceptual framework resistant to certain new evidence (especially logically incompatible evidence). Feminists who, from within a feminist conceptual framework, dismiss as unworthy of equal and serious consideration arguments for the biological inevitability of patriarchy would then be correctly described as "biased" in this second sense, i.e. as not offering a valueneutral, ahistorical, or noncontextual objectivity. In this sense, bias is a matter of degree as well as kind.

Given this second sense of 'bias', the proper question is not whether a feminist view is biased, but whether a feminist bias is a better bias than a patriarchal or androcentric bias. Feminists who argue that it is a better bias do so precisely because it is more inclusive and less partial. To be impartial on an issue is not to have no opinion or feelings about it. Nor is it to take some "value-neutral" stance outside any given conceptual framework, since
(I have claimed) no such stance is possible. Impartiality, like the critical thinking dispositions of openmindedness and interpersonal sensitivity, is always exercised from with some conceptual framework.

From a feminist point of view, impartiality consists partly in listening to points of view of those in subordinate positions, of those without established authority within the dominant culture, of those at the bottom of the hierarchy. It involves being sure that the felt experiences of women, however diverse those experiences may be, are part of theorybuilding. From a feminist point of view, impartiality requires inclusiveness. A patriarchal conceptual framework that supports or fails to challenge assumptions, beliefs, values and attitudes that serve to reinforce male domination and that omits the felt experiences, contributions, and perspectives of women, is more partial because less inclusive than one (e.g. a feminist conceptual framework) that does not. A feminist conceptual framework thereby provides a better bias ('bias' in the second sense).

Furthermore, since a feminist conceptual framework which is more inclusive of the realities of more people provides a better data base from which to make generalizations, it helps to ensure that the generalizations one makes are not biased in the first sense. That is, the bias ('bias' in the second sense) of a feminist conceptual framework contributes to its being less biased (in the first sense).

From a feminist point of view, then, a commitment to feminism is a commitment to impartiality and openmindedness (properly understood), and a commitment to impartiality and openmindedness (properly understood) is a commitment to feminism. Alison Jaggar expresses this viewpoint succinctly in her article "Teaching Sedition: Some Dilemmas of Feminist Pedagogy:"

Indeed, feminists believe that a genuinely impartial consideration of contemporary social life must generate inevitably a commitment to feminism . . . From the feminist point of view, it is not feminism that is irrational or biased, but rather positions that ignore or discount the specific interests of women. Far from constituting a disqualifying bias, feminist commitment is a defense against one very common and damaging form of bias. Impartiality is not undermined by feminism; 
instead, feminist commitment helps to safeguard impartiality. ${ }^{36}$

If what I have said is correct, a "proper understanding" of "openmindedness" requires an understanding of the nature and power of conceptual frameworks, particularly patriarchal ones.

\section{Teaching/Learning Critical Thinking: Some Feminist Considerations}

\section{I have argued that critical thinking is} always contextual in that it always occurs within a given conceptual framework. Current research on critical thinking suggests that critical thinking is extremely sensitive to context in other ways as well. According to Stephen Norris,

This is true for two reasons. First, the inferences and appraisals of inferences that a person can justify making depend on the background assumptions, level of sophistication, and concept of the task. Inferences that do not agree with those sanctioned by a test or with those a teacher might make do not necessarily indicate a critical thinking deficiency ... Second, critical thinking is sensitive to context because context can dramatically affect the quality of one's performance. This is a highly confirmed result in the area of deductive logical reasoning (Evans, 1982). Deductive logical reasoning is based on the form rather than on its content ... Despite this, people reason better deductively when dealing with thematic contexts, with contexts that relate to their personal experience, and when they do not have presumptions about the truth of the conclusion. In additon, deductive reasoning performance is lowered in contexts involving threats or promises. ${ }^{37}$

According to Norris, both the inferences one can justify making and the quality of one's ability to make inferences is sensitive to context, e.g. to the "background assumptions, level of sophistication, and concept of the task" as well as to whether the environment feels safe. Some inferences may be justified against one background set of assumptions but not others, or within one conceptual framework but not another. If, as Norris claims, "people reason better deductively when dealing with thematic contexts, with contexts that relate to their personal experience, and when they do not have presumptions about the truth of the conclu- sion," then a person's ability to reason well deductively is affected by conceptual frameworks.

The element of contextual sensitivity is also important to the effective teaching/learning of critical thinking. ${ }^{38}$ It raises the problem of the "transfer" of critical thinking to domains other than those in which the skill was originally taught. A discussion of the problem of transfer must attend to various levels of transfer: transfer within a restricted field of study to new examples within that field, transfer across disciplinary boundaries, and transfer into the thinking practices in which we engage in our everyday lives. ${ }^{39}$ An attention to the problems of transfer is an attention to context: the learner's background knowledge, assumptions, and experiences, and the nature of her "everyday life." One who manifests such contextual sensitivity manifests an important critical thinking disposition.

According to Norris, this general need for contextual (including interpersonal) sensitivity and for "teaching critical thinking for transfer"' is confirmed, even if there is as yet little detailed knowledge about what specifically makes students who have had direct instruction in critical thinking better thinkers or how to accomplish the desired transfer. ${ }^{40}$ To achieve this contextual sensitivity, teachers/learners must eventually come to recognize their own conceptual frameworks, see alternative conceptual frameworks, and, where possible, conduct discussions across conceptual frameworks.

It is because critical thinking is extremely sensitive to context that both the teaching and assessments of critical thinking abilities and performance must seek explicit indications of people's reasons for their conclusions. Otherwise, one will be unable to "differentiate between deficiencies in thinking abilities and differences in background assumptions and beliefs between the examiner and examinee." 41

Robert Swartz may be correct that, as a rule of inference, "Modus ponens is the same in science as in history." 42 But, if Norris' research conclusions are correct, then a person's ability to learn and use modus ponens may be very different in different contexts, 
including the contexts provided by science and history. One implication of Norris' view is that the ability to recognize, use, and assess inferences based on modus ponens will be affected by both the "safety" of the environment and the inferer's own prior knowledge. A learner's critical thinking performance and abilities may be significantly affected if the examples used and conclusions drawn are given from a very different conceptual framework. Failure to take seriously one's own conceptual framework ("point of view") as well as the learner's could also incline an evaluator to conclude, prematurely if not incorrectly, that the learner is not very good at deductive reasoning.

\section{Conclusion}

In this paper I have argued that an adequate conception of critical thinking must involve the recognition that critical thinking always takes place within some conceptual framework. In this respect, critical thinking must be understood as essentially contextual, i.e. sensitive to the conceptual framework in which it is conceived, practiced and learned or taught. What makes this contribution distinctively feminist is that it makes visible the ways in which patriarchal conceptual frameworks are relevant to the theory and practice of critical thinking.

Feminism changes the agenda of critical thinking by problematicizing old issues in new ways. If what I have said in this paper is correct or even plausible, then the link between critical thinking and feminism is much deeper and potentially more liberating than the current scholarship on critical thinking would suggest. The aims of each are interrelated and mutually reinforcing. It may be, then, that critical thinking is not simply a feminist issue. It may be that critical thinking must be feminist if it is truly to be what it purports to be, viz. reasonable and reflective activity aimed at deciding what to do or believe.

\section{Notes}

1 I do not take up directly the debate over the proper definition of critical thinking in this paper. Nor do I debate the related issues of the proper taxonomy of "critical thinking skills," whether critical thinking is "subject-area specific," or the most effective ways of teaching critical thinking. For a discussion of various views on critical thinking, see Barry K. Beyer's "Critical Thinking: What Is It?" Social Education (April, 1985): 270-276.

2 Robert H. Ennis, "Rational Thinking and Educational Practice," in Philosophy of Education (80th yearbook of the National Society for the Study of Education, Vol. 1), ed. by J. F. Soltis (Chicago: The National Society for the Study of Education, 1981), and more recently, "A Logical Basis for Measuring Critical Thinking Skills, ' Educational Leadership, 43 (October, 1985): 44-48, and "A Taxonomy of Critical Thinking Dispositions and Abilities," in Teaching Thinking Skills: Theory and Practice, ed. by Joan B. Baron and Robert J. Sternberg (New York: W.H. Freeman and Company, 1987), pp. 9-26. This definition is "sufficient for our purposes" because the position advanced in this paper would not change substantially even if some other definition of critical thinking currently in use is preferable.

3 For a more complete listing of critical thinking abilities and dispositions, see Ennis, "A Taxonomy of Critical Thinking Abilities and Dispositions," ibid. It is worth noting that according to current research, having a "critical spirit" (or "critical disposition") is as important in critical thinking as having certain skills (Stephen P. Norris, "Synthesis of Research on Critical Thinking," Educational Leadership, 42 (May, 1985): 44.

4 Richard Paul, for instance, argues that since "emotions and beliefs are always inseparably wedded together," empathy and passions are important in critical thinking. See Paul, "Dialogical Thinking: Critical Thinking Essential to the Acquisition of Rational Knowledge and Passions," in Teaching Thinking Skills, ibid., 127-148. This broad definiton seems to have two 
distinct advantages: it accommodates narrower definitions in terms of skills, while also being attractive from a feminist point of view. The latter is so because, as I argue in the paper, exclusive and oppositional dualisms (e.g. critical vs. creative thinking, reason vs. emotion) are viewed with extreme suspicion by many feminists.

5 Alison Jaggar provides a thorough analysis of the first four leading conceptions of feminism in her book, Feminist Politics and Human Nature (Totowa, N.J.: Rowman \& Allanheld, 1983), and a discussion of Black and Third World Feminism in Feminist Frameworks: 2nd Edition, eds. Alison M. Jaggar and Paula S. Rothenberg (New York: McGraw Hills, 1984). A discussion of ecological feminism vis-a-vis the other feminisms can be found in Karen J. Warren, "Feminism and Ecology: Making Connections," Environmental Ethics (Spring, 1987): 3-20.

6 This discussion of oppressive conceptual frameworks is a revised version of what I offered in my "Feminism and Ecology: Making Connections," ibid.

7 Elizabeth Dodson Gray, Green Paradise Lost (Wellesley Mass.: Roundtable Press, 1981), p. 20.

8 Although I do not argue for these claims here, arguments for ways in which Western culture, particularly Western philosophy, has sanctioned such valuehierarchical thinking can be found, e.g., in: Susan Bordo, The Flight to Objectivity: Essays on Cartesianism and Culture (Albany: Suny Press, 1987); Genevieve Lloyd, The Man of Reason: 'Male' and "Female" in Western Philosophy (Minneapolis: University of Minnesota Press, 1984); Carolyn Merchant, The Death of Nature: Women, Ecology, and The Scientific Revoltuion (San Fransisco: Harper \& Row, 1980).

9 See Jaggar, ibid., p. 96.

${ }^{10} \mathrm{I}$ discuss this point with regard to ecological feminism in my piece "The Power and Promise of Ecological Feminism," read at the American
Philosophical Association Eastern Division Meetings, Dec. 27-30, 1987.

11 Although many feminists argue that all the dominant cultures of Western history have been patriarchal, whether enlightened, reformed, feudal, capitalist, or socialist, I leave open here the question whether that is true.

12 In Western culture at least, women are presumed to be the ones to do so-called "women's work" (e.g. raising children, attending to domestic responsibilities, caregiving), i.e. work relegated primarily to the "private" sphere. So, while that work may have some status or value, typically it is status or value within a sphere generally taken to be of less seriousness, significance, or political importance than the "public sphere" of men's work.

13 Notice that calling a conceptual framework "patriarchal" does not mean that it is one held by all, or by only, males. To the extent that both males and females in contemporary culture are raised within a patriarchal conceptual framework, they will both be affected by that framework, even if, as men and women, they are affected by it in different ways and to different extents.

14 Other approaches to showing the link between critical thinking and feminism also could be used. For instance, one could show the ways in which understanding how the college and pre-college climate is "chilly for women" bears on understanding women student's abilities or dispositions to think critically, or how testing situations and measurements fail to use examples or situations which draw on the particular or cultural experiences of women. See Roberta M. Hall and Bernice R. Sadler, "The Clasroom Climate: A Chilly One For Women?' Project for the Status and Education of WOMEN, Association of American Colleges, 1818 R. Street NW, Washington, DC 20009.

15 For a helpful discussion of bias, and the unavoidable but potentially dangerous bias of a "point of view," see J. Anthony 
Blair's "What is Bias?" in Selected Issues in Logic and Communication, ed. Trudy Govier (Belmont, CA: Wadsworth Publishing: 1988): 93-103.

16 The examples are chosen from science and ethics because these two fields represent a wide range of issues concerning the making and assessing of so-called factual and value claims which are central to discussions of critical thinking. They thereby illustrate both the breadth and depth of feminist concerns about the nature and teaching of critical thinking.

17 Ruth Bleier, Science and Gender: A Critique of Biology and its Theories on Women (New York: Pergamon Press, 1984).

18 Bleier, "Introduction," in Feminist Approaches to Science, ed. by Ruth Bleier (New York: Pergamon Press, 1986), p. 2. I do not intend to defend Bleier's views here, or any of the other views given by the feminist scientists and feminist ethicsists cited. My objective is simply to use their views to show why and how the way critical thinking is conceived and practiced within patriarchal conceptual frameworks is a feminist issue.

19 Sherry B. Ortner was one of the first to address a similar question of interests to ecological feminists: "Are women closer to nature than men?" (Ortner, "Is Female to Male as Nature Is To Culture?" in Michelle Rosaldo and Louise Lamphere, eds., Woman, Culture, and Society (Stanford: Standford University Press, 1974), pp. 67-68. Ecological feminists raise the same sort of objection to this question "Are women closer to nature than men?', that I have raised here to the question "Are there biological differences between men and women?' 'For example, Joan Griscom argues that "the question is itself flawed" since "we are all part of nature, and since all of us, biology and culture alike, is part of nature" (Joan Griscom, "On Healing the Nature/Culture Split in Feminist Thought," Heresies 13: Feminism and Ecology, 4 (1981): 9.

20 See Donna Haraway, "Primatology is Politics by Other Means"' and Sarah
Blaffer Hrdy, "'Empathy, Polyandry, and the Myth of the Coy Female,' in Feminist Approaches to Science, ibid., pp. 77-118 and 119-146, respectively.

21 Bleier, "Introduction," Feminist Approaches to Science, p. 8.

22 Bleier, Science and Gender, p.29.

23 Ibid., p. 9.

24 Judith Jarvis Thomson, "A Defense of Abortion,' Philosophy and Public Affairs 1 (September, 1971): 47-66.

${ }^{25}$ See Kathryn Adelson, "Moral Revolution," in Women and Values: Readings in Recent Feminist Philosophy, ed. Marilyn Persall (Belmont, CA: Wadsworth, 1986): 291-309.

26 Ibid., p. 306.

27 Jane Roland Martin, Reclaiming A Conversation: The Ideal of the Educated Women (New Haven: Yale University Press, 1985), p. 197.

${ }^{28} \mathrm{As}$ in the preceding section on feminist science, my purpose here is not to resolve this important issue about bias in ethics. Nor is it to suggest that whatever bias exists in ethics requires revolutionary, rather than reformist, changes to remedy (as Addelson claims). Rather, it is to use recent feminist discussions in ethics to illustrate ways in which the charge of bias arises in ethics and what the bias has to do with conceptual frameworks.

29 Compare Evelyn Fox Keller's discussion of cytogeneticist Barbara McClintock's approach to her research of the maize plant. According to Keller, McClintock urges scientists to "let the material speak to you [the material in McClintock's case is the corn plant]" by developing a "feeling for the organism." (Evelyn Fox Keller, "Women, Science, and Popular Mythology,', in Machina Ex Dea: Feminist Perspectives on Technology, ed. Joan Rothschild (New York: Pergamon Press, 1983), p. 141). For a complete discussion of Keller's treatment of McClintock's work, see Keller, A Feeling for the Organism: The Life and Work of 
Barbara McClintock (San Fransisco: W. H. Freeman, 1983).

30 Bleier, Science and Gender, p. 107.

${ }^{31}$ Ibid.

32 Such considerations have led many feminist scientists to conclude that there is no single correct scientific methodology, and that scientific methodology cannot protect research and its conclusions from the investigator's biases, values and beliefs. See Bleier, Science and Gender, pp. 4-5.

${ }^{33}$ Similarly, if one operates from within a racist conceptual framework which assumes that nonwhites are genetically inferior to whites, it will be very difficult to take seriously the points of view that there are no relevant genetic difference between whites and nonwhites, that whites and blacks are equal, that "white supremacy" is a piece of ideology. It will be impossible to take those opposing views seriously if one continues to adhere to the basic assumptions of the racist conceptual framework.

34 Notice that I have not argued here for the view that only a feminist point of view is an "openminded" view. What I have claimed is that from a feminist point of view, openmindedness does not require taking seriously all points of view, since some points of view (e.g. that women ought to be treated as inferior to men) do not warrant serious consideration.

35 This is the notion of bias that Michael Scriven offers in his book Reasoning (New York: McGraw Hill, 1976): 208.

36 Alison M. Jaggar, "Teaching Sedition: Some Dilemmas of Feminist Pedagogy," Report from the Center for Philosophy and Public Policy, pp. 8-9.

37 Norris, ibid., p. 42. The reference to
Evans is to J. St. B.T. Evans, The Psychology of Deductive Reasoning (London: Routledge and Kegan Paul, 1982).

Space does not permit me to discuss the relevance of research on "feminist pedagogy" in this paper. For a discussion of such issues, see the journal Feminist Teacher; Mary Anne Wolff's “According to Whom? Helping Students Analyze Contrasting Views of Reality," Educational Leadership (October, 1986): 36-41; Charlotte Bunch and Sandra Pollack, eds. Learning Our Way: Essays in Feminist Education (Trumansburg, N.Y.: Crossing Press, 1983); Margo Culley and Catherine Portugues, eds. Gendered Subjects: The Dynamics of Feminist Teaching (Boston: Routledge and Kegan Paul, 1985); Bernice Fisher, "What is Feminist Pedagogy?' in Radical Teacher, 18 (1981): 20-24; Henry A. Giroux, Theory and Resistance in Education: A Pedagogy for the Opposition (South Hadley: Bergin and Garvey, 1983); Nancy Hoffman, "White Woman, Black Woman: Inventing an Adequate Pedagogy, " in Women's Studies Newsletter, 1-2 (1977): 21-24; Nancy Porter, "Liberating Teaching," in Women's Studies Quarterly, X (1982): 19-24.

39 Robert J. Swartz, "Critical Thinking, the Curriculum, and the Problem of Transfer," in Thinking: Progress in Research and Teaching. ed. David N. Perkins et al. (Hillsdale, N.J.: L. Erlbaum Assoc., 1987), p. 283.

40 Norris, ibid., p. 44.

41 Ibid., p. 42.

42 Swartz, ibid., p. 270.

Professor Karen J. Warren, Philosophy Department, Macalester College, 1600 Grand Avenue, Saint Paul MN 55105 